Special Issue of the 8th International Advances in Applied Physics and Materials Science Congress (APMAS 2018)

\title{
Prediction of Round Jet Flow with Artificial Neural Networks
}

\author{
U. $\operatorname{KESEN}^{a, *}$, T. ŞIŞMAN ${ }^{b}$ AND İ. ÇAVUŞOĞLU ${ }^{b}$ \\ ${ }^{a}$ Marmara University, Faculty of Technology, Mechatronics Eng. Dept., Göztepe, Istanbul, Turkey \\ ${ }^{b}$ Marmara Univ., Vocational School of Technical Sciences, Machine and Metal Technology Dept., \\ Göztepe, Istanbul, Turkey
}

\begin{abstract}
In this study, an artificial neural networks model was established by using experimental measurement values at low speed subsonic wind tunnel of which length was $75 \mathrm{~cm}$ and experiment test section was $32 \mathrm{~cm} \times 32 \mathrm{~cm}$, and model results were compared with experimental values and then, the prediction was made for the unmeasured tunnel stream values. In the wind tunnel, when the jet velocity was $25 \mathrm{~m} / \mathrm{s}$, four tunnel velocities, $0,5,10$, and $20 \mathrm{~m} / \mathrm{s}$ were used. At the four measurement stations; $x / D=0.3, x / D=12.5, x / D=31.2$, and $x / D=50$ experimental measurements were made by using hot wire anemometer. Plain circular jet flows at $x / D=0.3$ and $x / D=50$ stations with average tunnel flow velocities of $7.5 \mathrm{~m} / \mathrm{s}$ and $15 \mathrm{~m} / \mathrm{s}$ were studied by using artificial neural networks. The data was obtained and evaluated by graphics.
\end{abstract}

DOI: 10.12693/APhysPolA.135.609

PACS/topics: jet flow, Artificial Neural Network (ANN), wind tunnel experiment

\section{Introduction}

Although there have been intensive experimental and computational studies on the structure of jet flows, the studies about plain jet flows are new. This study is the continuation of the work done by Inan and Sisman, where plain circular pipe flows were studied experimentally and numerically. In this study, artificial neural network (ANN) method is used to calculate the intermediate values in the previous study [1].

Many researchers used ANN method to evaluate experimental and numerical studies. Chawla et al. made the design and testing of power plant and power control systems by using ANN [2]. Gulez et al. protected electrical and electronic equipment from excessive current by using ANN [3]. Sarikas et al. diagnosed thyroid gland disease by using fuzzy logic and neural network [4]. Kesen and Yildirim made an educational simulator [5]. In another study, Kesen et al. made an application as the evaluation of a product development performance by using ANN [6]. Ekmekci et al. used ANN circular jet flows and estimated velocity values at non-measured stations and showed the results in graphics [7].

In the ANN model, tunnel velocities, length ratios, and radial distances were taken as input. Modeling was made by these data and network was constructed. Then, the relevant radial velocity distribution was obtained as the output. Using the data obtained from this network, mean velocity values at $7.5 \mathrm{~m} / \mathrm{s}$ tunnel velocities were predicted and dimensionless velocity distributions at these intervals are shown in Fig. 1.

*corresponding author; e-mail: ukesen@marmara.edu.tr
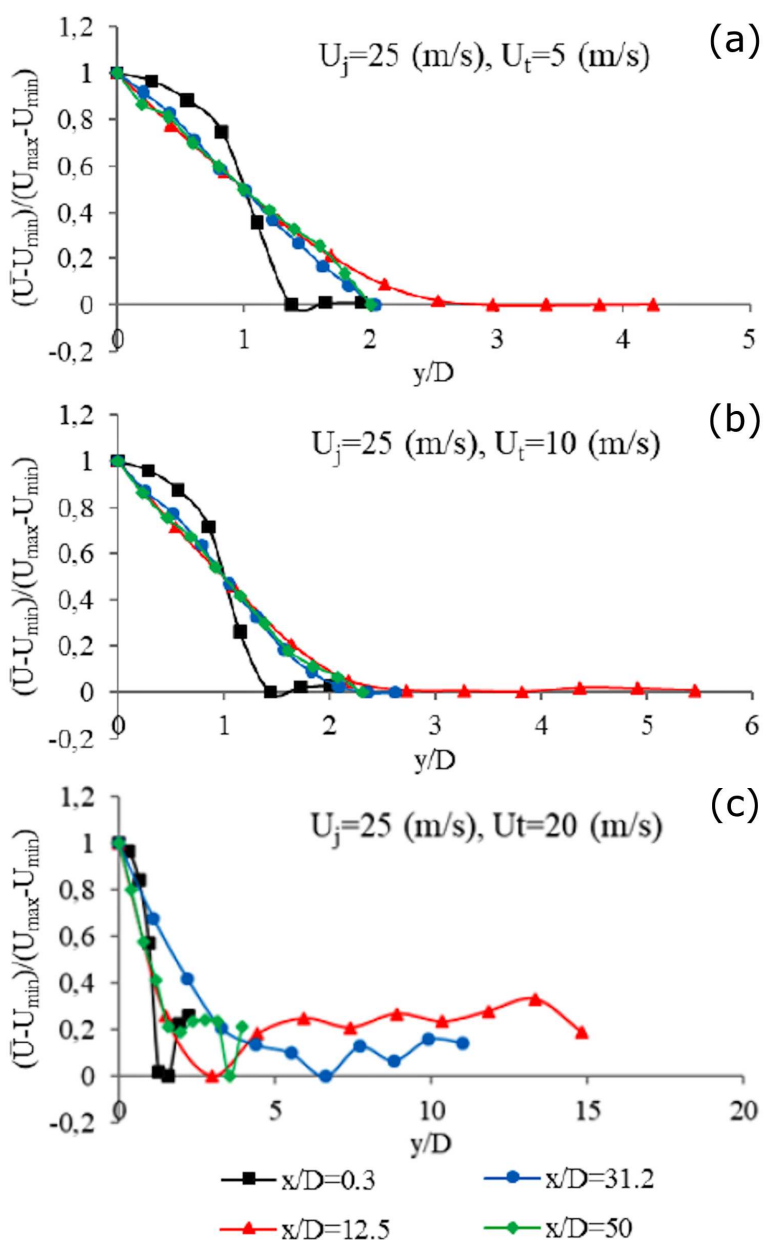

Fig. 1. Dimensionless velocity distributions for plain circular tube for $25 \mathrm{~m} / \mathrm{s}$ jet velocity, Tunnel velocity: (a) $5 \mathrm{~m} / \mathrm{s}$, (b) $10 \mathrm{~m} / \mathrm{s}$, and (c) $20 \mathrm{~m} / \mathrm{s}[8]$. 


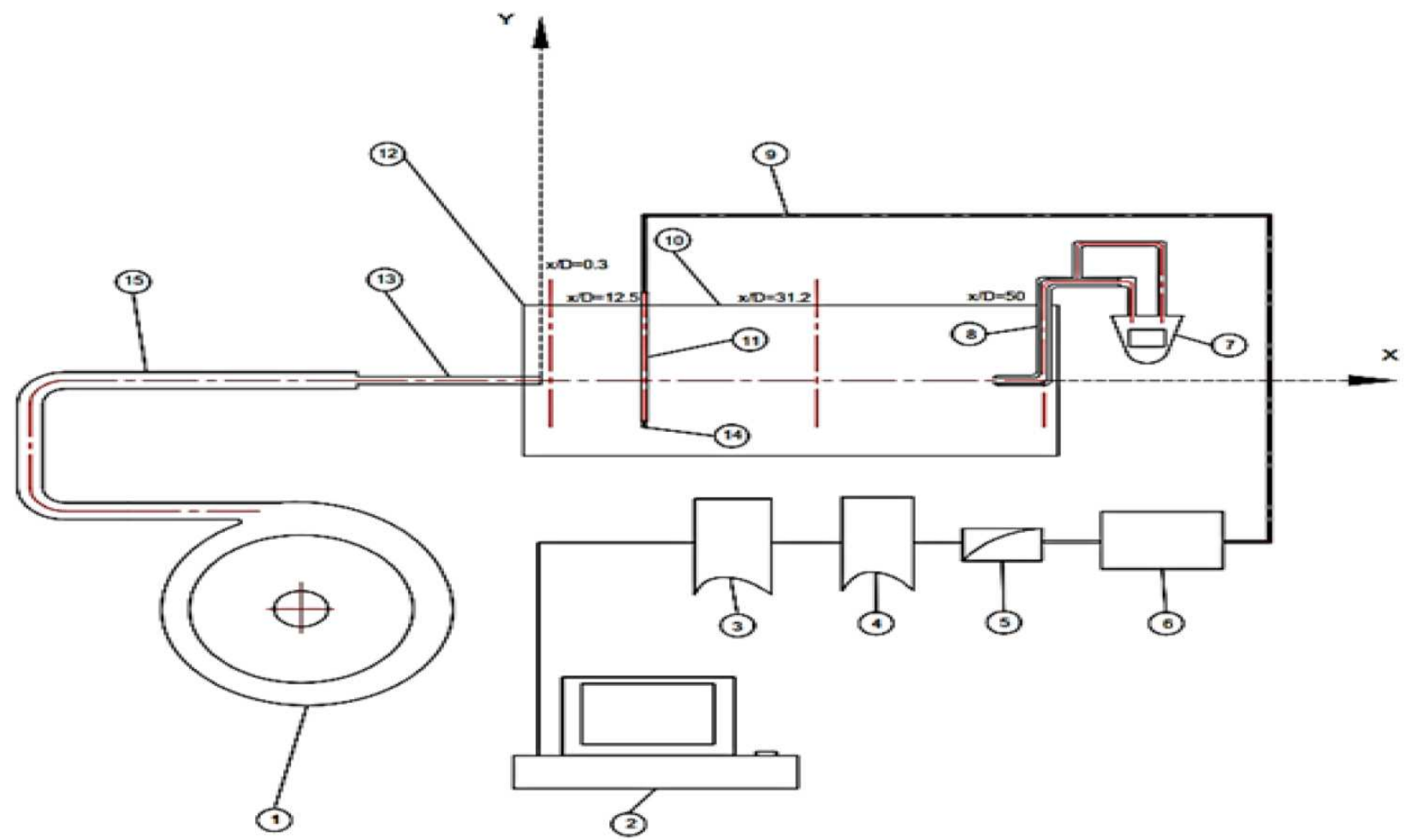

Fig. 2. Layout of experimental setup: 1 - jet air generator, 2 - computer, 3 - data analysis element, $4-$ time series, 5 - linearization, 6 - Wheatstone bridge and servo-amplifier, 7 - digital Pitot static tube screen, 8 - pitot tube, 9 - coaxial cable, 10 - experimental chamber, 11 - probe support, 12 - wind tunnel experimental chamber inlet, 13 - jet tube element, 14 - probe, 15 - tube connection element [8].

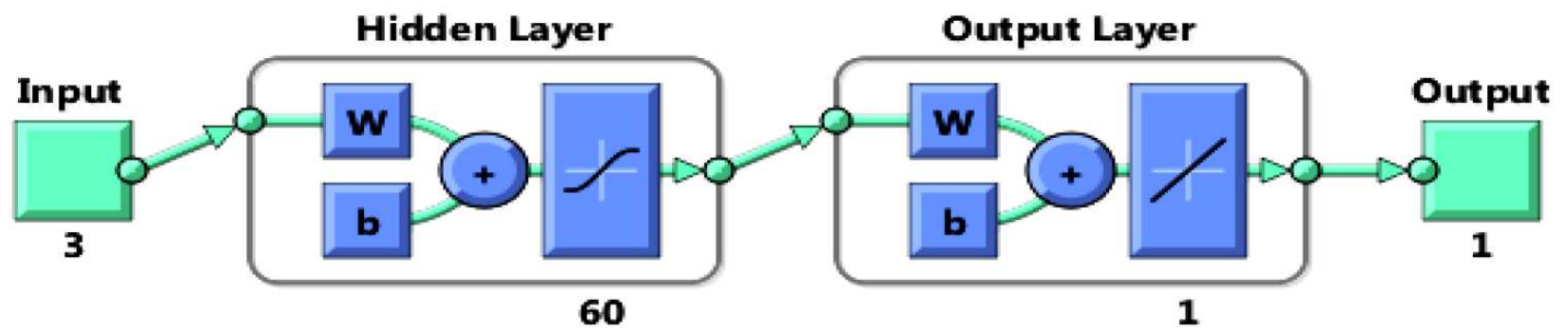

Fig. 3. The structure of ANN.

\section{Experimental method}

Experimental studies were performed in the subsonic air tunnel. To obtain jet flow, a secondary air generator was used as shown in Fig. 2 [1].

Previously the authors have conducted experimental and numerical studies about inner grooved circular jet flow. Jet axial velocity $U_{e}$, jet half width $b$, the Reynolds number in respect of jet half width $R e D$ values were presented in tables and graphics [1]. The layout of the experimental setup is shown in Fig. 2.

Using the data obtained from the measurements, dimensionless flow profiles and velocity distributions for $25 \mathrm{~m} / \mathrm{s}$ jet velocity were plotted as shown in Fig. 1.
In this study, ANN model with multi layered forward feedback propagation was used $[2,3]$. The main reason for using multilayered feed-forward back propagation ANN model [4] is that they are globally recognized approximations, and in terms of the data availability this model is the best performer among ANN models [9]. ANN is made of layers. In this ANN model, 50 neurons are defined in the hidden layer and one neuron in the exit layer. Tunnel velocity, length, ratio and radial distances are defined as inputs. ANN structure is shown in Fig. 3.

In ANN, learning algorithms are used to instruct the network. In this study algorithm of training adaptive Levenberg-Marquardt has been used for its simplicity and high performance rates. 

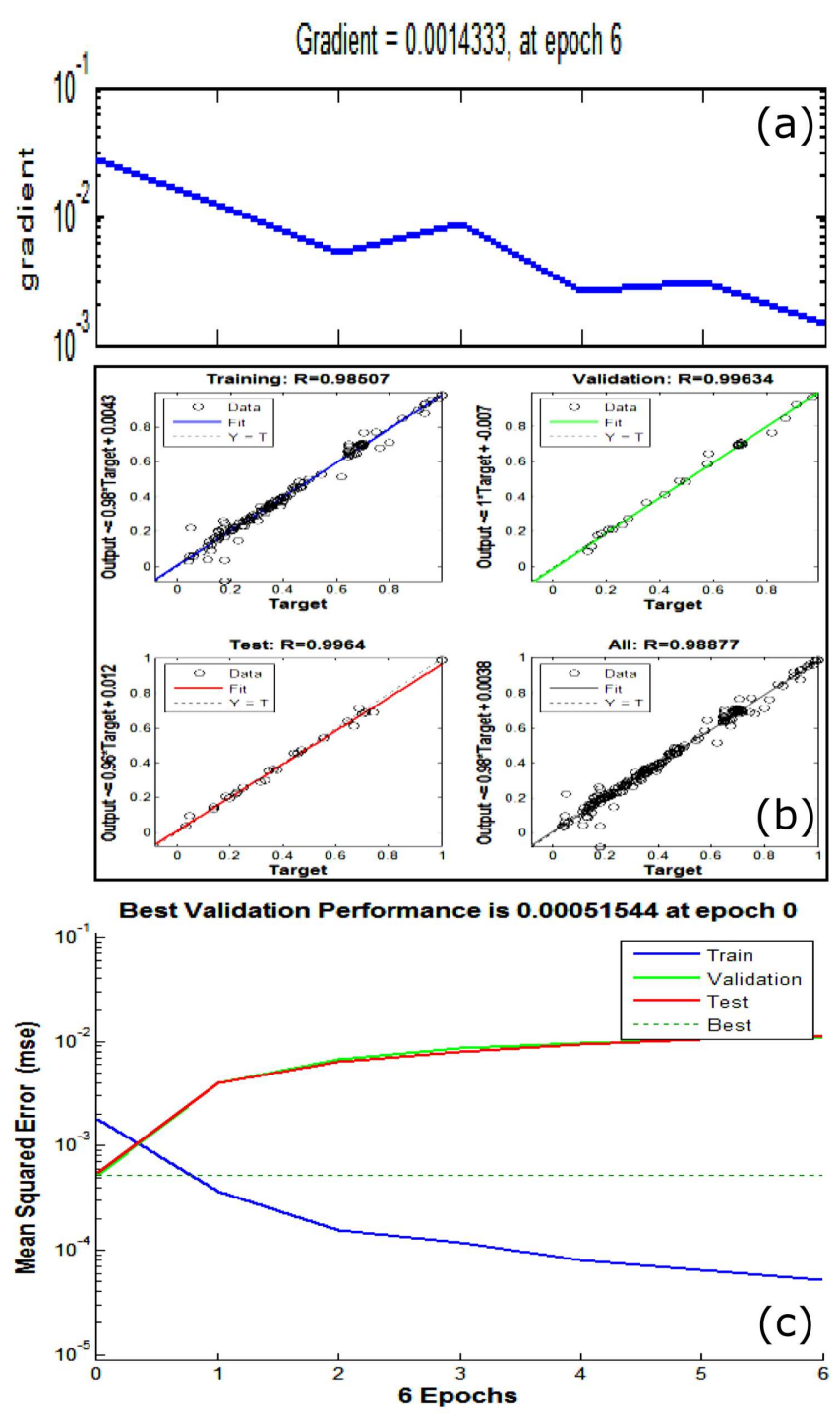

Fig. 4. (a) Gradient descent with momentum used in the training of ANN model, (b) testing and validation data for performance values used in the training of ANN model, (c) MSE of ANN model.

The scheme is shown in Fig. 4. Gradient descent with momentum has been used in the training of ANN model, for testing and validation data and finally mean squared error (MSE) of ANN model has been submitted.

ANN model is instructed as $97 \%$ and it confirms obtained experimental data of $98 \%$ as seen in Fig. 4 for 7.5 and $15 \mathrm{~m} / \mathrm{s}$ tunnel velocities where experimental measurements were not performed, dimensionless velocity distributions obtained by ANN were given in Fig. 5 .

\section{Results and discussion}

For the plain circular tubes, jet flow measurements were performed under the conditions when the tunnel flow velocity was 5,10 , and $20 \mathrm{~m} / \mathrm{s}$ and jet flow velocity was $25 \mathrm{~m} / \mathrm{s}$. The obtained graphics were presented in Fig. 1. Four measurement stations $(x / D=0.3$,

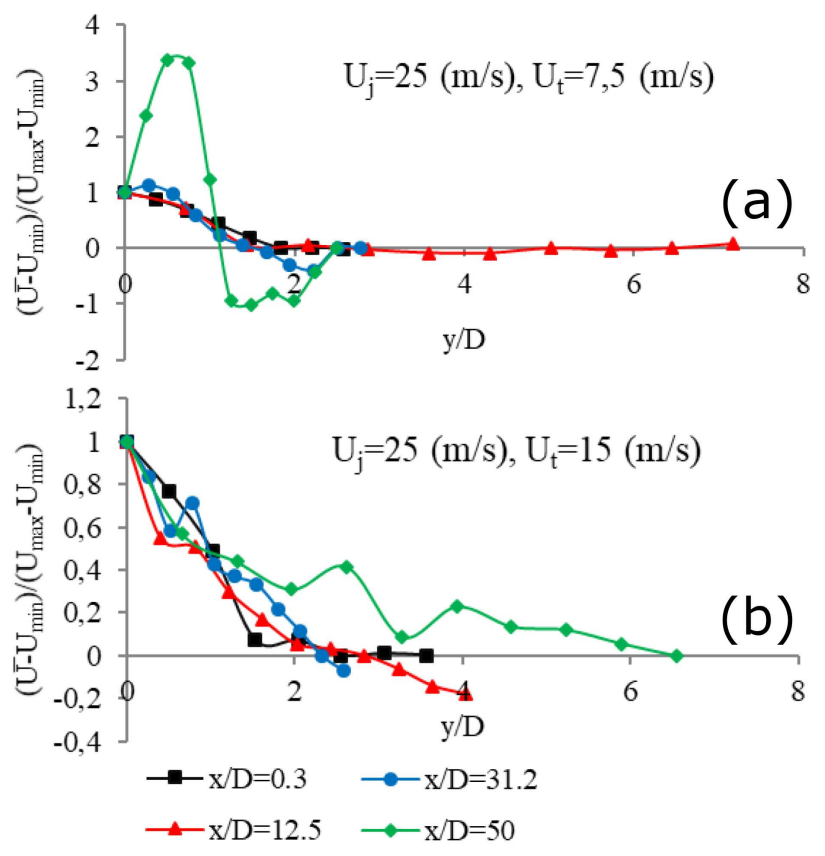

Fig. 5. Dimensionless velocity distributions for plain circular tube for $25 \mathrm{~m} / \mathrm{s}$ jet velocity. Tunnel velocities: (a) $7.5 \mathrm{~m} / \mathrm{s}$, (b) $15 \mathrm{~m} / \mathrm{s}$.

$x / D=12.5, x / D=31.2$ and $x / D=50)$ were determined in experimental chamber for jet flow measurements. The measurements were taken vertically from the predetermined points. In this study, the velocity values given in dimensionless graphics with the predetermined intervals were predicted by using ANN for the tunnel velocities of $7.5 \mathrm{~m} / \mathrm{s}$ and $15 \mathrm{~m} / \mathrm{s}$. The predicted average velocity values were then given in Fig. 5 as dimensionless graphics.

It can be seen from the dimensionless graphics when the tunnel velocity was $7.5 \mathrm{~m} / \mathrm{s}$ jet flow retained its structure in the $x / D=0.3$ and $x / D=12.5$ measurement stations. In the measurement station $x / D=12.5$. Inan has reported that it was indicated for the measurements deviating from the $y$ axis, the jet structure was lost within the tunnel included in tunnel flow [10].

For $x / D=31.2$, the jet flow structure was completely lost within the tunnel. This led to the fluctuations, which were caused by the presence of inner grooved pipes, on graphs. It was indicated that there was a low turbulence at $x / D=50$. Both results showed that the tunnel flow was then stabilised.

\section{Conclusion}

Inan has also reported that when the tunnel velocity was $15 \mathrm{~m} / \mathrm{s}$ in the dimensionless graphs, the jet flow structure was completely retained in the $x / D=0.3$ and $x / D=12.5$ measurement stations. But just after the measurement station $x / D=31.2$, the jet flow structure was subject to loss and this loss continued in $x / D=50$ measurement station. In the end jet flow was replaced by 
tunnel flow. It was indicated that the turbulence formed the axially measured velocities in $x / D=31.2$ and in $x / D=50$ stations [10]. The tunnel velocity and jet velocity were obtained to be higher, and therefore, this result is similar with Inan's study. The jet flow was lost in a short time. Furthermore, when the ratio between tunnel velocity and jet velocity became smaller, jet flow structure retained partly. From the comparison of both graphics (ANN and experimental) for the minimum and maximum values, it was obtained that core, transition, and turbulence regions were shown in both investigations. It was indicated that predictions found by ANN were in agreement with experimental work [10].

\section{References}

[1] T. Inan, T. Sisman, Acta Phys. Pol. A 127, 1145 (2015).

[2] G. Chawla, M.S. Sachdev, G. Ramakrishna, IFAC Proc. Vol. 39, 125 (2006).

[3] K. Gulez, R. Yumurtaci, M. Uzunoglu, in: Proc. 6th Int. Conf. on Optimization of Electrical and Electronic Equipments, Brasov (Romania) 1998, 2002, p. 241.
[4] E. Çanayaz, A. Sarıkaş, U. Kesen, in: Proc. 2nd Int. Symp. on Innovative Technologies in Engineering and Science (Isites'2014), Karabük (Turkey) 2014, Ed. Naci Çağlar, p. 715.

[5] U. Kesen, T. Yildirim, in: Proc. 15th Int. Symp. on Computer and Information Sciences (ISCIS XV), Istanbul (Turkey) 2000, Ed. M.Y. Yildirim, p. 545.

[6] U. Kesen, Y. Yayla, T. Yıldırım, in: Innovations and Applications in Smart Systems Symposium (ASYU 2010), Kayseri (Turkey) 2010, Ed. T. Yildirim, p. 95.

[7] I. Ekmekci, A.T. Inan, H. Oner, A. Onat, Energy Educat. Sci. Technol. A Energy Sci. Res. 29, 1431 (2012).

[8] T. Sisman, M.Sc. Thesis, Marmara University, Turkey 2013.

[9] G. Chawla, M.S. Sachdev, G. Ramakrishna, in: Proc. 2008 Annual IEEE India Conf., Kanpur 2008, p. 234.

[10] A.T. Inan, Acta Phys. Pol. A 131, 403 (2017). 